www.jmscr.igmpublication.org

Impact Factor 5.84

Index Copernicus Value: 83.27

ISSN (e)-2347-176x ISSN (p) 2455-0450

crossref DOI: https://dx.doi.org/10.18535/jmscr/v5i5.22

Journal Of Medical Science And Clinical Research

IGM Publication

An Official Publication of IGM Publication

\title{
Clinical profile of Leprosy Patients who attended Department of Dermatology, Government Vellore Medical College Hospital during 2012-13 to 2015-16
}

Authors

\section{Dr Dharmambal. $\mathbf{C}^{1}$, Dr Vasanthamoorthy. $\mathbf{R}^{2}$, Dr Balachander. $\mathbf{J}^{3}$,}

Dr Somasundaram. $\mathrm{A}^{4}$

${ }^{1,2,3}$ Department of Dermatology, Government Vellore Medical College Hospital, Vellore 632011, India

${ }^{4}$ Department of Public Health, 359, Annasalai, DMS Campus, TamilNadu, India

Corresponding Author

Dr C.Dharmambal

Department of Dermatology, Govt. Vellore Medical College Hospital, Vellore, Tamil Nadu, India - 632011

Telephone: +91 9443812849, Email: cdharmambal@gmail.com

\begin{abstract}
Introduction: Leprosy is a communicable disease caused by M. leprae mainly affecting the skin and nerves. In India the prevalence rate has declined from 4.2 in 2001 to 0.68 in 2015. Despite reaching elimination level and progressively declining trends in the state of TamilNadu, new cases are being reportedl and are likely to continuously occur. We conducted a retrospective study on the leprosy patients to understand the clinical profile of the leprosy cases in Government Vellore Medical College.

Materials and Methods: The study is a descriptive retrospective study. We did a retrospective analysis of the 179 cases who attended Government Vellore Medical College; Vellore during April 2012 to March 2016Statistical analysis was done with Epi info software.

Results: The number of cases in 2012-13 was 52 which declined to 31 in 2015-16. The proportion of male cases among adults is $63 \%$. Majority of the cases (37\%) were more than 45 years of age. Borderline Tuberculoid (60\%) was the major type based on clinical finding.13 cases were pure neuritic type. The proportion of multibacillary cases was $70 \%$.

Discussion: Despite Leprosy Elimination strategies many cases are reported and they are lately detected. The decline shown in our study is consistent with the trend in the state. The majority patients belonged to the late age group (> 45years of age). Late diagnosis is a cause for concern both for the individual, in terms of complications and disability, and for the contacts in terms of transmission of the disease. Late diagnosis may lead to complications and also adversely affect the quality of life. Child cases were 10\% and the occurrence of child cases indirectly indicates the presence of infection in the community. Majority of the cases are Multibacillary which could act as source of infection

Conclusion: Active case search strategy is to be intensified and sustained. Intensive IEC campaigns to be undertaken on early health seeking, and avoidance of stigma and discrimination. Health providers are to be continuously trained.
\end{abstract}




\section{Introduction}

Leprosy is a communicable disease caused by Mycobacterium leprae mainly affecting the skin and nerves. It progresses slowly with an average incubation period of 3 years and can affect all ages and both sexes. Currently worldwide the prevalence rate of leprosy is on the decline. According to WHO prevalence rate of less than 1 case per 10,000 is considered as elimination level. In India the prevalence rate has declined from 4.2 in 2001 to 0.68 in 2015. Similarly Annual New Case detection has decreased from 5.9 to 0.97 during the same time period ${ }^{1} .32$ States/ UTs had attained the level of leprosy elimination and 542 districts $(82.5 \%)$ out of total 657 districts also achieved elimination by March 2014.

TamilNadu has achieved the elimination level $(0.38 / 10000)$ i.e. a prevalence rate of less than 1 case per 10000 populations. A total of 3604 new cases were detected during the year 2014-15 ${ }^{1} .3 \%$ of country's case load was from TamilNadu. The proportion of child case was 12.68 in 2014-15 (457 cases). 389 cases of deformities were identified in 2014-15 with 202 cases of grade I and 187 cases of grade II deformities. In Vellore district of TamilNadu the prevalence rate has been less than one $0.28 / 10000$ and the ANCDR is 3.29 in 2014-15.

Despite reaching elimination level and progressively declining trends in the state of TamilNadu, new cases are being reported ${ }^{1}$ and are likely to continuously occur due to the long incubation period of the disease. To sustain this elimination level the crucial strategy is to identify the cases early and treat them thereby reducing the source, as leprosy is transmitted from untreated case of leprosy ${ }^{2}$ Early detection is also imperative to prevent complications such as nerve damage, deformities etc. Further the stigma associated with leprosy is still a challenge.

We conducted a retrospective study on the leprosy patients' data and have described the clinical profile of the leprosy cases.

\section{Objectives}

The objective of our study is to describe the Clinical Profile of the new leprosy patients attending the dermatology outpatient department in Government Vellore Medical College during the period from April 2012 to March 2016.

\section{Materials and Methods}

The study is a descriptive retrospective study. We did a retrospective analysis of the case records and registers of the Leprosy patients who attended the Dermatology outpatient department of Government Vellore Medical College, Vellore during the period from April 2012 to March 2016. Records of 179 Leprosy patients who reported during this period were analysed. The register and the treatment cards maintained for the leprosy case patients were used as source data. Informed consent was obtained from the clients who willfully accepted. Statistical analysis was done with Epi info software.

\section{Results}

The total number cases of Leprosy were 179. The number of cases in 2012-13 was 52 which declined to 31 in 2015-16. Total child cases were 16. The difference in decline between between the adult cases and the child cases is statistically significant (P Value 0.01) by chi square trend analysis. The proportion of male cases among adults is $63 \%$ but the difference is not statistically significant. The proportion of cases those who were more than 45 years of age was $37 \%$. Borderline Tuberculoid (60\%) was the major type based on clinical finding. Nerve thickening was seen in $71 \%$ of the patients. 13 cases were pure neuritic type. The proportion of multibacillary cases was $70 \%$ though statistically not significant by chi square proportion. There were 19 old cases with default cases 12 and relapse 7 cases. 
Table 1: Characteristics of Leprosy cases in Government Vellore Medical College during the period 2012-13 to 2015-16

\begin{tabular}{|c|c|c|}
\hline Characteristics & $\#(n=179)$ & Proportion \% \\
\hline \multicolumn{3}{|l|}{ Year } \\
\hline $2012-13$ & 52 & 29 \\
\hline $2013-14$ & 51 & 28 \\
\hline $2014-15$ & 45 & 25 \\
\hline $2015-16$ & 31 & 17 \\
\hline \multicolumn{3}{|l|}{ Adult Vs Child } \\
\hline Adult & 167 & 93 \\
\hline Child & 12 & 7 \\
\hline \multicolumn{3}{|c|}{ Age Distribution } \\
\hline Child & 16 & 8.9 \\
\hline $16-24$ & 22 & 12.3 \\
\hline $25-34$ & 33 & 18.4 \\
\hline $35-44$ & 30 & 16.8 \\
\hline $45 \&$ above & 78 & 43.6 \\
\hline \multicolumn{3}{|l|}{ Gender } \\
\hline Male & 112 & 63 \\
\hline Female & 67 & 37 \\
\hline \multicolumn{3}{|l|}{ Clinical type } \\
\hline MB & 126 & 70 \\
\hline PB & 53 & 30 \\
\hline \multicolumn{3}{|c|}{ Ridley Joplings Classification } \\
\hline TT & 24 & 13 \\
\hline BT & 108 & 60 \\
\hline BB & 13 & 7 \\
\hline $\mathrm{BL}$ & 14 & 8 \\
\hline LL & 7 & 4 \\
\hline Pure Neuritis & 13 & 7 \\
\hline
\end{tabular}

Table 2. Leprosy Cases by type of Cases among adults in Government Vellore Medical College during the period 2012-13 to 2015-16

\begin{tabular}{|l|c|c|}
\hline & MB & PB \\
\hline $2012-13$ & 38 & 14 \\
\hline $2013-14$ & 33 & 18 \\
\hline $2014-15$ & 28 & 17 \\
\hline $2015-16$ & 27 & 4 \\
\hline & 126 & 53 \\
\hline
\end{tabular}

Table 3. Leprosy cases $(n=179)$ by WHO Classification, in Government Vellore Medical College during the period 2012-13 to 2015-16

\begin{tabular}{|l|c|c|c|}
\hline & MB & PB & Total \\
\hline Males & 83 & 21 & 104 \\
\hline Females & 37 & 22 & 59 \\
\hline Child Male & 2 & 6 & 8 \\
\hline Child female & 2 & 6 & 8 \\
\hline & 124 & 55 & 179 \\
\hline
\end{tabular}

Fig 1. Declining trend in the cases of Leprosy the in Government Vellore Medical College during the period 2012-13 to 2015-16

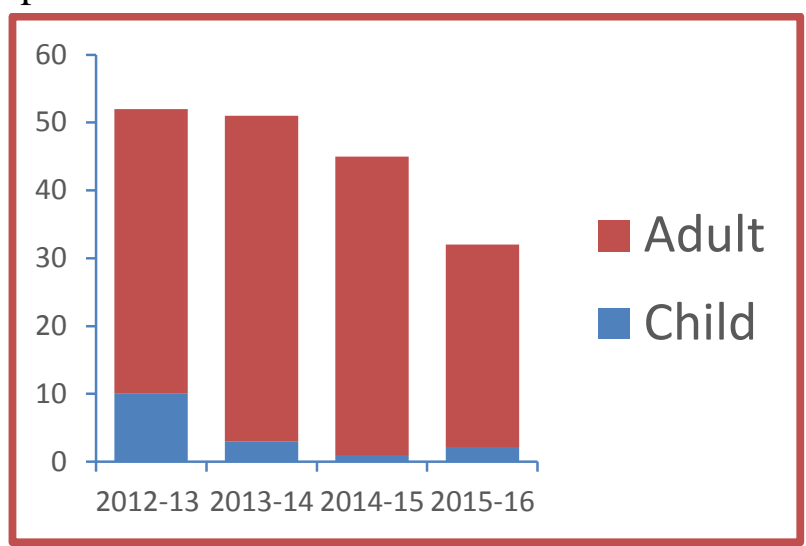

Fig 2. Distribution of Leprosy Cases by Gender in in Government Vellore Medical College during the period 2012-13 to 2015-16

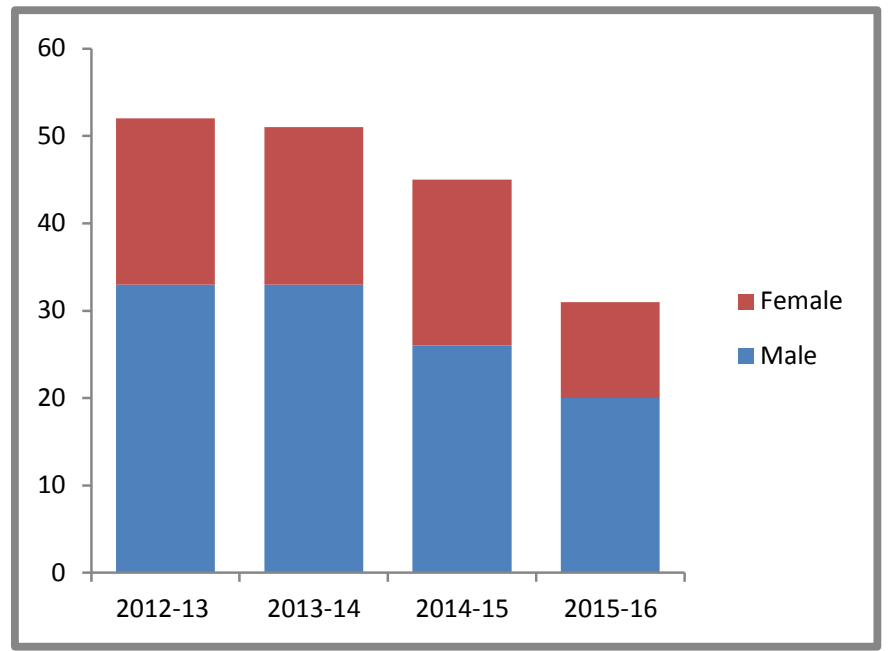

Fig 3. Distribution of Leprosy Cases by age in Government Vellore Medical College during the period 2012-13 to 2015-16

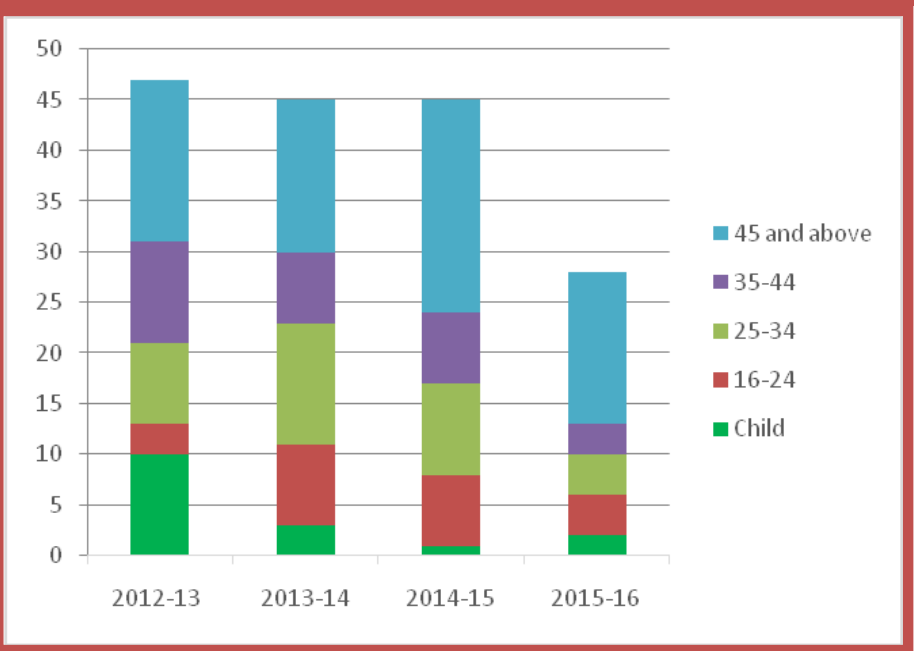


Figure 4. Leprosy cases by Ridley Jopling's Classification in Government Vellore Medical College during the period 2012-13 to 2015-16

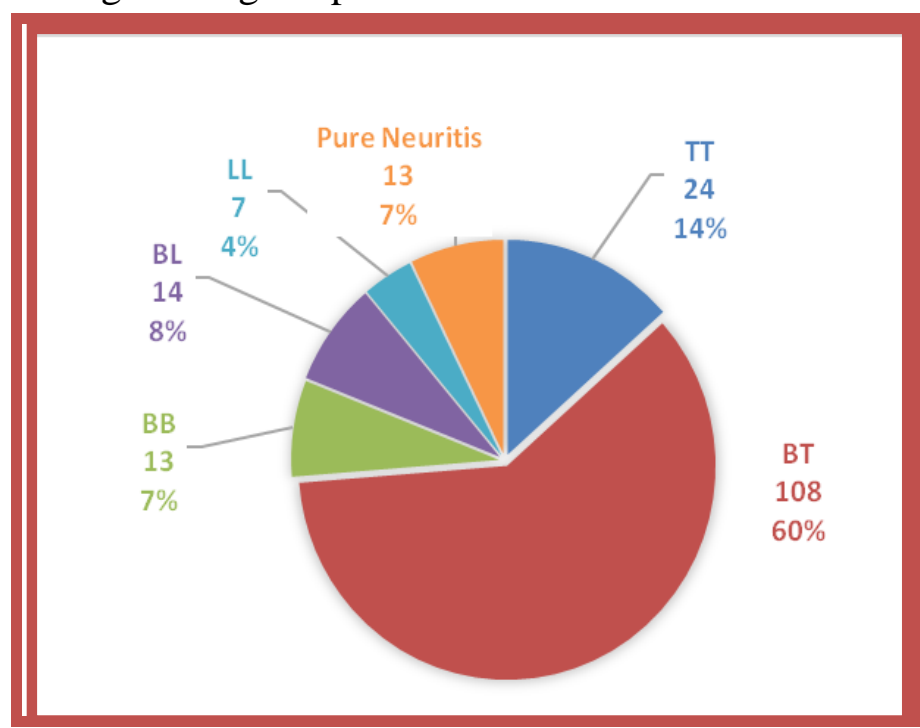

\section{Discussion}

The WHO has recently launched strategy to accelerate towards leprosy free World with key strategies such as detecting cases early before visible disabilities occur, targeting detection among higher risk groups in highly endemic areas or communities and improving access for marginalized populations. Despite Leprosy Elimination strategies many cases are reported and they are lately detected.

From our study data the number of cases declined year by year. This is consistent with the trend in the state. ${ }^{1}$ Except 19 cases others were previously undiagnosed or new cases diagnosed recently. The majority patients belonged to the late age group (> 45 years of age). Late diagnosis is a cause for concern both for the individual, in terms of complications and disability, and for the contacts in terms of transmission of the disease. Late diagnosis may lead to complications and also adversely affect the quality of life ${ }^{3}$.

Lack of awareness and stigma attached to the disease is a cause for late reporting. Similarly child cases are indirect indicator for undiagnosed cases in the community ${ }^{4}$ and also a challenge for sustenance of low prevalence at elimination level. $10 \%$ of the cases were child cases in our study. $70 \%$ of the cases are Multibacillary which means they can act as high source of infection for contacts $^{5,6}$. Contact with a leprosy patient is also major determinant in incident leprosy. In our study, we could elicit clear cut contact history in only $5 \%$ of the cases.

\section{Conclusion}

We conclude that early diagnosis to be reiterated among Health care providers. For that active case search strategy is to be intensified and sustained. Intensive IEC campaigns to be undertaken on early health seeking, and avoidance of stigma and discrimination. Health providers are to be continuously trained and motivated to identify cases to initiate treatment at the earliest in order to delink the transmission chain as well as prevent disability among patients.

\section{References}

1. Central Leprosy Division Directorate General of Health Services Nirman Bhawan, New Delhi - 110011. NLEP Progress Report for the year 2014-15: pg 4

2. Centre for Disease Control available from Hansens Diseease Leprosy Transmission https:// www.cdc.gov/ leprosy/ transmission/

3. Lustosa, Anselmo Alves, Nogueira, Lídya Tolstenko, Pedrosa, José Ivo dos Santos, Teles, João Batista Mendes, \& Campelo, Viriato. (2011). The impact of leprosy on health-related quality of life. Revista da Sociedade Brasileira de Medicina Tropical, 44(5), 621626. https://dx.doi.org/ 10.1590/ S003786822011000500019

4. Ezenduka, Charles et al. "CostEffectiveness Analysis of Three Leprosy Case Detection Methods in Northern Nigeria." Ed. Christian Johnson. PLoS Neglected Tropical Diseases 6.9 (2012): e1818. PMC. Web. 25 Apr. 2017.

5. Pinheiro RO, de Souza Salles J, Sarno EN, Sampaio EP. Mycobacterium leprae-hostcell interactions and genetic determinants 
in leprosy: an overview. Future microbiology. 2011;6(2):217-230. doi:10.2217/fmb.10.173.

6. Oral mucosa as a source of Mycobacterium leprae infection and transmission, and implications of bacterial DNA detection and the immunological status Martinez, T.S. et al. Clinical Microbiology and Infection, Volume 17 , Issue $11,1653-1658$. 